\title{
Progress in Advanced Photovoltaic Thermal Collectors
}

\author{
Prof. Dr. Kamaruzzaman Sopian \\ Solar Energy Research Institute \\ Universiti Kebangsaan Malaysia \\ 43600 Bangi Selangor, Malaysia \\ ksopian@ukm.edu.my
}

\begin{abstract}
Conventional photovoltaic thermal (PVT) collectors have been classified to air-based, water-based, and dual-fluid PVT collectors. Materials like nanofluids, phase change material (PCM) and nano-enhanced phase change material (NEPCM) have been incorporated, in various research studies, into PVT collectors. Different components such as concentrators, fins, heat exchangers, control devices, etc., have been investigated for their effect on the collector and system output. Many advanced types of PVT collectors have been considered in the literature by combining different active and/or passive components such as the (i) Concentrated PVT with thermoelectric generators (CPVT-TEG), (ii) nanofluid cooled CPVTTEG, and (iii) nanofluid-based PVT with PCM/NEPCM. However, to date the gap between proposed concepts of PVT systems and their actual implementation in the industry is growing. This calls for the need to establish a more comprehensive research foundation and thus it is necessary to distinguish between conventional and advanced types of PVT collectors and to provide an overview of recent progress on the topic. The aims of this review paper are to (i) present the conceptual design of different advanced PVT collectors, (ii) describe and assess recent developments in these collectors, and (iii) critically review the state of research in the field of advanced PVT systems.
\end{abstract}

